\title{
Studies of Isotopic Exchange Reactions Between Alkali Iodides and Butyl Iodide in Acetone
}

\author{
ULF ISACSSON* and GÖRA N WIKA NDER \\ Division of Physical Chemistry, University of Umeå, S-901 87 Umeå, Sweden
}

\begin{abstract}
Isotopic exchange reactions between butyl iodide and alkali iodides in acetone at $25^{\circ} \mathrm{C}$ have been studied for various concentrations of the ionic iodide. Kinetic data have been analysed by means of the Acree equation $k=k_{\mathrm{i}} \alpha+k_{\mathrm{m}}(1-\alpha)$, where $k$ is the observed secondorder rate constant, $k_{\mathrm{i}}$ and $k_{\mathrm{m}}$ are rate constants for the reactions of ions and ion-pairs, respectively, and $\alpha$ is the degree of dissociation of the salt. The results do not indicate significant reactivity of the alkali iodide ion-pairs.

According to the Acree hypothesis $k_{\mathrm{i}}$ should be independent of the nature of the cation. The result of this research supports this assumption.

Association constants of the salts were determined by conductivity measurements. Data were analysed by means of the Fuoss-Onsager and Shedlovsky conductance equations.
\end{abstract}

\begin{abstract}
few years ago an investigation concerning the ion-pair reactivity in isotopic Aexchange reactions was started by Beronius. ${ }^{1}$ Ion-pairs of lithium chloride ${ }^{1}$ and bromide ${ }^{2}$ in acetone seem to be unreactive species, whereas the more loosely bound ion-pairs of tetrabutyl ammonium chloride and bromide in this solvent ${ }^{3}$ may be kinetically active. Alkali iodides in methanol have also been studied. ${ }^{4}$ However, the slight association of ions into ion-pairs in this latter case makes the estimates of the ion-pair reactivities more uncertain.

The purpose of the present investigation was to examine whether alkali iodide ion-pairs are reactive in the exchange of ${ }^{131} \mathrm{I}$ with butyl iodide in acetone.
\end{abstract}

\section{EXPERIMENTAL}

Reagents. Sodium, potassium, rubidium, and cesium iodides (Merck, suprapur.) were dried for $2 \mathrm{~h}$ at $120^{\circ} \mathrm{C}$ and allowed to cool in a vacuum desiccator. Potassium chloride (Merck, suprapur.), for calibration of conductivity cells, was dried for $2 \mathrm{~h}$ at $250^{\circ} \mathrm{C}$ and cooled as above.

* Present address: Division of Physical Chemistry, the Royal Institute of Technology, S-100 44 Stockholm 70, Sweden.

Acta Chem. Scand. 26 (1972) No. 4 
Acetone (Merck, p.a.) was purified according to Smith et al. ${ }^{5}$ The specific conductivity of the purified acetone varied between $1.6 \times 10^{-8}$ and $2.3 \times 10^{-8} \mathrm{ohm}^{-1} \mathrm{~cm}^{-1}$. The permittivity, $\varepsilon$, at $25^{\circ} \mathrm{C}$ was determined from several measurements using a Ferisol Type M $803 \mathrm{~A}$ Q-meter. The value $\varepsilon=20.57 \pm 0.01$ (standard deviation) was obtained. The literature value $\varepsilon=20.70^{\circ}$ was used in calculations below. The corrected density at $25^{\circ} \mathrm{C}$ was $d_{4}^{25} 0.78430 \pm 0.00002 \mathrm{~g} \mathrm{ml}^{-1}$ (standard deviation), determined by means of a Lipkin pycnometer. ${ }^{8}$ The viscosity at $25^{\circ} \mathrm{C}$ was determined with a KPG Ubbelohde Viscometer $^{\circ}$ and found to be $\eta=0.003038 \pm 0.000001$ (standard deviation) poise, in good agreement with the literature value, ${ }^{6} \eta=0.003040$ poise. The last value was used in the calculations.

The conductivity water, used in calibrating the cells, was obtained from a quartz distilling apparatus. Its specific conductance was less than $1 \times 10^{-8} \mathrm{ohm}^{-1} \mathrm{~cm}^{-1}$.

Butyl iodide (Kebo, technical grade) was distilled in a column filled with copper turnings in order to remove any traces of hydrogen iodide or iodine. The purified product was stored in the dark. Its density at $25^{\circ} \mathrm{C}$, corrected to vacuum, was $1.6070 \mathrm{~g} \mathrm{ml}^{-1}$.

Preparation of alkali radioiodides. Radioactive iodide, $\mathrm{Na}{ }^{131} \mathrm{I}$, was obtained in a dilute aqueous thiosulphate solution from the Atomic Energy Establishment, Kjeller, Norway. The water was removed by dissolving the solution in methanol followed by evaporation. The active salt was then dissolved again in a suitable quantity of methanol and stored in the dark. To obtain the other alkali radioiodides from $\mathrm{Na}^{131} \mathrm{I}$ the following procedure was used:

A Dowex $50 \mathrm{~W}$-X8 ion exchanger was saturated with respect to the cation in question and the aqueous solution of the active sodium salt was passed through. The water in the eluate was removed as described above.

Preparation of solutions. Stock solutions and solutions for kinetic and conductivity measurements were prepared by weight. All weights were corrected to vacuum.

Kinetic procedure. The isotopic exchange reaction between organic and inorganic iodide was followed electroanalytically according to a procedure given in Refs. 10 and 11 .

The performance of the electrolytic cell was the same as in Ref. 2. The cell was filled with inactive alkali iodide solution $(50 \mathrm{ml})$. Between 5 and $20 \mu \mathrm{Ci}{ }^{131} \mathrm{I}$, dissolved in methanol, were transferred to a test-tube and the solvent evaporated. About $3 \mathrm{ml}$ of the inactive solution were then transferred from the cell to the test-tube. After dissolving, the radioactive salt was retransferred to the cell.

The silver anode area was $0.126 \mathrm{~cm}^{2}$ and the stirring rate $100 \mathrm{rpm}$.

The electrode reaction, $\mathrm{Ag}+\mathrm{I}^{-} \rightarrow \mathrm{AgI} \rightarrow 0^{-}$, was investigated with respect to current efficiency. A current density of $5500 \mu \mathrm{A} \mathrm{cm}-2 \mathrm{mM}^{-1}$ alkali iodide was chosen in the kinetic measurements. This corresponds to a point on the plateau of the current efficiency vs. current density curve.

The reaction was started by adding $0.08-0.13 \mathrm{ml}$ butyl iodide by means of a microsyringe. For three systems (KI, RbI, CsI, respectively) the amount of the organic iodide was determined to within $\pm 0.05 \mathrm{mg}$ by weighing the syringe before and after the addition on a Mettler Micro Balance, model M5. For the exchange between sodium iodide and butyl iodide, $S_{\infty}$, the specific activity at equilibrium, was measured and the amount of organic iodide calculated as described in Ref. 12. In cases where high accuracy is desired the observed $S_{\infty}$-values must be corrected for depositions during the reaction. Eqn. 23 in Ref. 13 was used for that purpose.

The electrolysis times varied from 14 to $68 \mathrm{~s}$. To minimize the error in the velocity coefficient ${ }^{13}$ the electrolyses were performed after 2 half-lives of exchange. About $0.25 \%$ of the ionic iodide in the reaction mixture was deposited on each electrode.

Radioactivity measurements. The beta activity of the electrodes was measured by means of a proportional counter. The activity readings were corrected for dead-time losses, background counts, and decay of ${ }^{131} \mathrm{I}$. The standard deviation of the counting rate was reduced to $\pm 0.3 \%$ or less.

Conductivity measurements. A Leeds and Northrup 4666 bridge was used for determining the conductances, $A$, of solutions of alkali iodides in acetone. The conductivity cells used have previously been described. ${ }^{14}$ The Lind-Zwolenik-Fuoss ${ }^{15}$ method was used for calibrating the cells. Four cells, three of them with constants of the order $0.07 \mathrm{~cm}^{-1}$ and one with a constant of the order $0.22 \mathrm{~cm}^{-1}$, were used. The measurements were performed at $25.00 \pm 0.01^{\circ} \mathrm{C}$. To reduce frequency dependence extrapolation to infinite frequency was made. 
Table 1. Equivalent conductances in acetone at $25^{\circ} \mathrm{C}$.

\begin{tabular}{|c|c|c|c|}
\hline \multicolumn{2}{|c|}{ Run A } & \multicolumn{2}{|c|}{ Run B } \\
\hline$c \times 10^{4}$ & $\operatorname{cm}^{2} \Omega^{-1}$ equiv. ${ }^{-1}$ & $\begin{array}{l}c \times 10^{4} \\
M\end{array}$ & $\mathrm{~cm}^{2} \Omega^{-1}$ equiv. ${ }^{-1}$ \\
\hline \multicolumn{4}{|c|}{ Sodium iodide } \\
\hline $\begin{array}{c}1.1700 \\
1.7667 \\
3.0107 \\
3.9263 \\
5.1542 \\
6.6877 \\
13.996 \\
16.364 \\
22.766 \\
24.596 \\
\mathbf{3 6 . 0 6 6} \\
\end{array}$ & $\begin{array}{l}190.26 \\
187.72 \\
182.77 \\
179.51 \\
176.70 \\
172.25 \\
159.74 \\
157.26 \\
150.51 \\
148.59 \\
140.88 \\
\end{array}$ & $\begin{array}{c}1.3731 \\
2.1830 \\
3.3226 \\
4.4325 \\
5.7969 \\
7.4338 \\
13.904 \\
16.866 \\
25.182 \\
32.616\end{array}$ & $\begin{array}{l}188.46 \\
185.75 \\
181.51 \\
177.80 \\
174.80 \\
170.61 \\
159.59 \\
156.78 \\
148.34 \\
142.80\end{array}$ \\
\hline \multicolumn{4}{|c|}{ Potassium iodide } \\
\hline $\begin{array}{c}0.8715 \\
3.6027 \\
5.3972 \\
8.8732 \\
13.029 \\
19.523 \\
23.601 \\
30.225 \\
\end{array}$ & $\begin{array}{l}192.01 \\
180.08 \\
174.89 \\
167.55 \\
160.77 \\
152.64 \\
148.51 \\
143.08\end{array}$ & $\begin{array}{c}1.0554 \\
4.4177 \\
6.7519 \\
10.443 \\
13.834 \\
21.592 \\
26.438 \\
31.877 \\
\end{array}$ & $\begin{array}{l}190.48 \\
177.64 \\
171.67 \\
164.55 \\
159.60 \\
150.52 \\
145.79 \\
141.58 \\
\end{array}$ \\
\hline \multicolumn{4}{|c|}{ Rubidium iodide } \\
\hline $\begin{array}{c}1.1079 \\
2.0798 \\
3.1475 \\
5.0937 \\
6.8369 \\
11.301 \\
16.565 \\
18.522 \\
22.494 \\
28.141\end{array}$ & $\begin{array}{l}193.41 \\
188.34 \\
183.94 \\
177.05 \\
172.17 \\
162.05 \\
154.07 \\
151.41 \\
146.71 \\
141.49\end{array}$ & $\begin{array}{c}1.2013 \\
1.6814 \\
2.5104 \\
3.1577 \\
4.3678 \\
5.6584 \\
11.352 \\
15.919 \\
16.209 \\
21.440 \\
26.511 \\
\end{array}$ & $\begin{array}{l}193.11 \\
189.64 \\
186.36 \\
183.30 \\
178.73 \\
175.03 \\
161.72 \\
154.83 \\
154.14 \\
147.69 \\
143.18 \\
\end{array}$ \\
\hline \multicolumn{4}{|c|}{ Cesium iodide } \\
\hline $\begin{array}{c}0.7845 \\
1.1532 \\
2.0067 \\
2.3557 \\
5.7861 \\
9.7928 \\
11.095 \\
13.016 \\
14.328 \\
16.532\end{array}$ & $\begin{array}{l}197.20 \\
194.10 \\
189.13 \\
186.99 \\
173.02 \\
161.98 \\
159.40 \\
155.33 \\
152.88 \\
149.51\end{array}$ & $\begin{array}{c}2.1332 \\
2.7877 \\
4.5685 \\
4.8625 \\
8.4637 \\
10.170 \\
12.320 \\
12.847 \\
16.268\end{array}$ & $\begin{array}{l}188.33 \\
184.51 \\
177.34 \\
176.17 \\
165.14 \\
161.24 \\
156.70 \\
155.57 \\
150.06\end{array}$ \\
\hline
\end{tabular}


Table 2. Second-order rate constants, $k$, at $25^{\circ} \mathrm{C}$ for exchange of ${ }^{131} \mathrm{I}$ between alkali iodides, AI and butyl iodide at different concentrations.

\begin{tabular}{|c|c|c|c|}
\hline $\begin{array}{l}\text { Expt } \\
\text { No. }\end{array}$ & $\underset{\mathrm{M}}{[\mathrm{AI}]} \times 10^{4}$ & $\underset{\mathbf{M}}{[\mathrm{BuI}]} \times 10^{4}$ & $\mathbf{M}^{-1} \stackrel{k}{\min ^{-1}}$ \\
\hline \multicolumn{4}{|c|}{ Sodium iodide } \\
\hline $\begin{array}{l}1 \\
2 \\
3 \\
4 \\
5 \\
6 \\
7 \\
8\end{array}$ & $\begin{array}{c}3.860 \\
7.733 \\
12.76 \\
19.62 \\
29.45 \\
39.19 \\
59.12 \\
79.02\end{array}$ & $\begin{array}{l}109.1 \\
109.1 \\
104.5 \\
105.4 \\
134.6 \\
184.9 \\
185.2 \\
190.5\end{array}$ & $\begin{array}{l}4.144 \\
3.967 \\
3.835 \\
3.760 \\
3.634 \\
3.503 \\
3.397 \\
3.268\end{array}$ \\
\hline \multicolumn{4}{|c|}{ Potassium iodide } \\
\hline $\begin{array}{r}1 \\
2 \\
3 \\
4 \\
5 \\
6 \\
7 \\
8 \\
9 \\
10\end{array}$ & $\begin{array}{c}0.9641 \\
3.858 \\
7.604 \\
11.51 \\
19.07 \\
28.90 \\
38.85 \\
57.72 \\
77.12 \\
96.53\end{array}$ & $\begin{array}{l}117.6 \\
111.8 \\
119.4 \\
120.7 \\
165.0 \\
187.9 \\
218.7 \\
219.1 \\
203.3 \\
223.2\end{array}$ & $\begin{array}{l}4.149 \\
3.973 \\
3.863 \\
3.787 \\
3.640 \\
3.537 \\
3.411 \\
3.238 \\
3.136 \\
3.051\end{array}$ \\
\hline \multicolumn{4}{|c|}{ Rubidium iodide } \\
\hline $\begin{array}{r}1 \\
2 \\
3 \\
4 \\
5 \\
6 \\
7 \\
8 \\
9 \\
10 \\
\end{array}$ & $\begin{array}{c}2.529 \\
4.856 \\
4.891 \\
8.043 \\
12.89 \\
20.19 \\
24.55 \\
30.72 \\
39.87 \\
50.08 \\
\end{array}$ & $\begin{array}{l}149.6 \\
145.0 \\
149.9 \\
149.4 \\
149.7 \\
135.0 \\
144.9 \\
149.2 \\
153.9 \\
150.8 \\
\end{array}$ & $\begin{array}{l}3.921 \\
3.842 \\
3.843 \\
3.764 \\
3.614 \\
3.454 \\
3.399 \\
3.347 \\
3.157 \\
3.089 \\
\end{array}$ \\
\hline \multicolumn{4}{|c|}{ Cesium iodide } \\
\hline $\begin{array}{l}1 \\
2 \\
3 \\
4 \\
5 \\
6 \\
7 \\
8 \\
9\end{array}$ & $\begin{array}{c}1.165 \\
2.222 \\
4.425 \\
7.338 \\
9.661 \\
11.73 \\
16.24 \\
22.33 \\
29.76\end{array}$ & $\begin{array}{l}141.4 \\
137.6 \\
144.2 \\
141.8 \\
158.1 \\
139.4 \\
155.4 \\
172.9 \\
176.0\end{array}$ & $\begin{array}{l}4.064 \\
3.968 \\
3.826 \\
3.704 \\
3.640 \\
3.603 \\
3.456 \\
3.356 \\
3.258\end{array}$ \\
\hline
\end{tabular}

Acta Chem. Scand. 26 (1972) No. 4 


\section{RESULTS}

Equivalent conductances for the four salts studied are quoted in Table 1 for various molar concentrations. Compilations of kinetic data for the four systems studied are given in Table 2 . The second-order rate constant, $k$, is defined by the expression $k=R / b c$, in which $R$ is the rate of exchange according to McKay, ${ }^{16} b$ the concentration of the organic iodide, and $c$ the concentration of the inorganic iodide. Average temperature in each run has been measured (range $24.99-25.07^{\circ} \mathrm{C}$ ). All rate constants, $k$, are corrected to $25.00^{\circ} \mathrm{C}$ according to the Arrhenius equation. In making these calculations the value of $15 \mathrm{kcal}$ $\mathrm{mol}^{-1}$ was used for the activation energy. All concentrations of the salts given in Table 2 are corrected for electrolyses at zero reaction time and for dilution during the addition of the organic iodide. The degree of dissociation, $\alpha$, of the alkali iodide was calculated as previously described. ${ }^{1}$ Two sets of $\alpha$-values have been calculated, one using the association constant according to the FuossOnsager equation ${ }^{17}$ and one using the association constant according to the Shedlovsky ${ }^{18}$ equation. In evaluating the activity coefficient in the DebyeHückel equation, the value 20.70 was used for the permittivity of the solvent and values given in Tables 3 and 4 for the distance of closest approach of the ions in the ion-pair $(\stackrel{a}{)}$.

Table 3. Conductance parameters of alkali iodides in acetone at $25^{\circ} \mathrm{C}$ according to the Fuoss-Onsager equation of 1957.

\begin{tabular}{|c|c|c|c|c|}
\hline Salt & $\begin{array}{c}K_{\mathrm{A}} \\
\mathrm{M}^{-1}\end{array}$ & $\begin{array}{c}\Lambda_{0} \\
\mathrm{~cm}^{2} \Omega^{-1} \text { equiv. }^{-1}\end{array}$ & $\begin{array}{c}a \times 10^{8} \\
\mathrm{~cm}\end{array}$ & $\begin{array}{c}\sigma_{A} \\
\%\end{array}$ \\
\hline NaI & $124 \pm 2.0$ & $200.5 \pm 0.08$ & 5.4 & 0.21 \\
KI & $120 \pm 2.3$ & $200.3 \pm 0.07$ & 4.8 & 0.16 \\
RbI & $192 \pm 1.6$ & $204.8 \pm 0.07$ & 5.6 & 0.17 \\
CsI & $264 \pm 1.1$ & $207.3 \pm 0.04$ & 5.5 & 0.10 \\
\hline
\end{tabular}

Table 4. Conductance parameters of alkali iodides in acetone at $25^{\circ} \mathrm{C}$ according to the Shedlovsky equation.

\begin{tabular}{|c|c|c|c|}
\hline Salt & $\begin{array}{c}K_{\mathrm{A}} \\
\mathrm{M}^{-1}\end{array}$ & $\begin{array}{c}A_{0} \\
\mathrm{~cm}^{2} \Omega^{-1} \text { equiv. }\end{array}$ & $\begin{array}{c}\boldsymbol{a} \times 10^{8} \\
\mathrm{~cm}^{a}\end{array}$ \\
\hline NaI & $155 \pm 1.9$ & $199.6 \pm 0.25$ & 3.11 \\
KI & $167 \pm 1.2$ & $199.8 \pm 0.17$ & 3.49 \\
RbI & $228 \pm 1.6$ & $204.2 \pm 0.20$ & 3.64 \\
CsI & $312 \pm 1.1$ & $207.1 \pm 0.11$ & 3.85 \\
\hline
\end{tabular}

${ }^{a}$ Sum of crystallographic radii. ${ }^{7}$

Dissociation of alkali iodides. In order to interpret the kinetic data it was necessary to know dissociation constants, $K_{\mathrm{D}}$, of the alkali iodides in acetone. Conductivity measurements were therefore undertaken. The equipment and

Acta Chem. Scand. 26 (1972) No. 4 
technique used for determining equivalent conductance, $\Lambda$, were as outlined in the experimental section and is described in detail in Ref. 14.

Analysis by means of the Fuoss-Onsager theory. The conductance data in Table 1 were analyzed by means of the Fuoss-Onsager equation, ${ }^{17}$

$$
\Lambda=\Lambda_{0}-S \sqrt{c \alpha}+E c \alpha \log c \alpha+J c \alpha-K_{\mathrm{A}} c \alpha f^{2} \Lambda
$$

where $A$ and $\Lambda_{0}$ have their usual meanings, $c$ is the molar salt concentration, $\alpha$ the degree of dissociation, and $K_{\mathrm{A}}$ the association constant. The mean activy coefficient, $f$, is defined by

$$
\begin{gathered}
\log f=-\frac{A \sqrt{c \alpha}}{1+B a \sqrt{c \alpha}}(1: 1 \text {-electrolyte }) \\
A=1.8246 \times 10^{6} /(\varepsilon T)^{3 / 2} \\
B=50.29 \times 10^{8} / \sqrt{\varepsilon T}
\end{gathered}
$$

where $\varepsilon$ is the permittivity of the solvent, $T$ the absolute temperature, and $a$ the ion-size parameter. The parameters $S$ (Onsager limiting slope), $E$ and $J$ are defined by equations given in Ref. 3 .

To obtain $\Lambda_{0}, K_{\mathrm{A}}$ and $a$, conductance data were fitted to eqn. (1), using an iterative method previously described. ${ }^{19}$ The relative standard deviation in $\Lambda, \sigma_{\Lambda}$, as well as the standard deviation of $\Lambda_{0}$ and $K_{\mathrm{A}}$ was calculated as described in Ref. 19. Points, deviating by more than three standard deviations in $\Lambda$, were discarded and a further curve fitting undertaken.

Analysis by means of the Shedlovsky equation. To obtain a comparison of the parameters $\left(\Lambda_{0}, K_{\mathrm{A}}\right)$ derived from the Fuoss-Onsager equation, data in Table 1 were analyzed by means of the semi-empirical Shedlovsky conductance equation, ${ }^{18}$

$$
\frac{1}{\Lambda S}=\frac{1}{\Lambda_{0}}+\frac{K_{\mathrm{A}} c \Lambda S f^{2}}{\Lambda_{0}^{2}}
$$

To evaluate $\Lambda_{0}$ and $K_{\mathrm{A}}$ a computer program described in Ref. 1 was used. Note that $S$ in eqn. (3) does not have the same meaning as $S$ in eqn. (1). For the definition of $S$ in eqn. (3), see, for instance, Ref. 1. Calculations were performed with the aid of a CDC 3200 computer. The results are grouped together in Tables 3 and 4.

As can be seen from Table 5, values of $K_{\mathrm{A}}$ differ greatly for the two different equations. The Shedlovsky equation gives higher $K_{\mathrm{A}}$-values (throughout). The difference can be as large as $40 \%$ (potassium iodide). For $\Lambda_{0}$ the agreement is good.

\section{DISCUSSION}

If iodide ions as weil as alkali iodide ion-pairs are reactive and the exchange is a mixed $\mathrm{S}_{\mathrm{N}} 1-\mathrm{S}_{\mathrm{N}} 2$ reaction, the total rate of exchange can be represented by the relation

$$
R=k_{1} b+k_{\mathrm{i}} b c \alpha+k_{\mathrm{m}}(1-\alpha) b c
$$


Table 5. Comparison of conductance parameter.

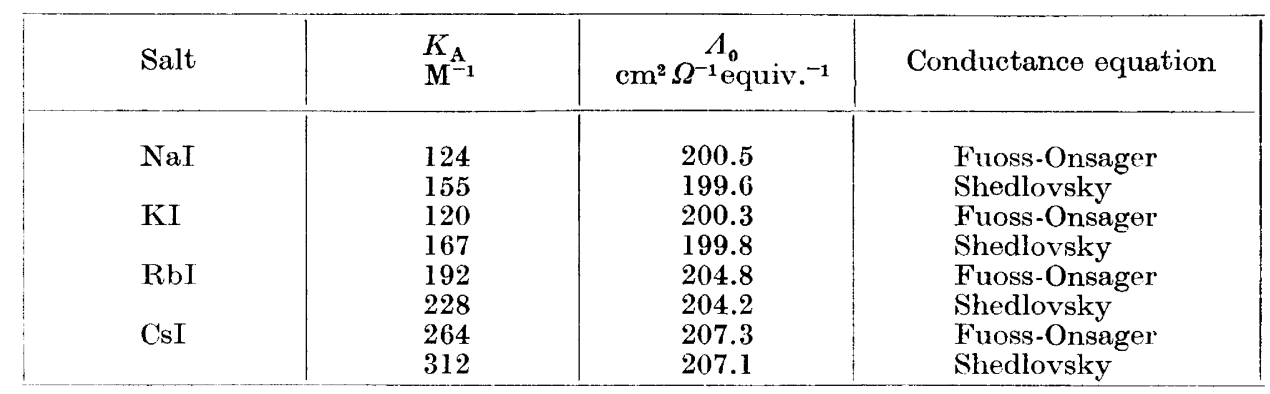

where $k_{1}$ is a first-order rate constant, $k_{\mathrm{i}}$ and $k_{\mathrm{m}}$ rate constants for $\mathrm{S}_{\mathrm{N}} 2$ exchange of ions and ion-pairs, respectively, and $\alpha$ the degree of dissociation of the salt. For low alkali iodide concentration, when $\alpha \approx 1$, the term containing $k_{\mathrm{m}}$ in eqn. (4) may be omitted. With these conditions eqn. (4) can be written

$$
R / b=k_{1}+k_{\mathrm{i}} c \alpha
$$

A plot of $R / b$ vs. $c \alpha$ should give a straight line with slope $k_{\mathrm{i}}$ and intercept $k_{1}$. Analysis of data in Table 2 give graphs all passing through the origin, indicating no $\mathrm{S}_{\mathrm{N}} 1$ contribution to the reaction rate. This is illustrated in Fig. 1. If, however, $k_{\mathrm{m}} \neq 0$ and the concentrations are sufficiently high, the

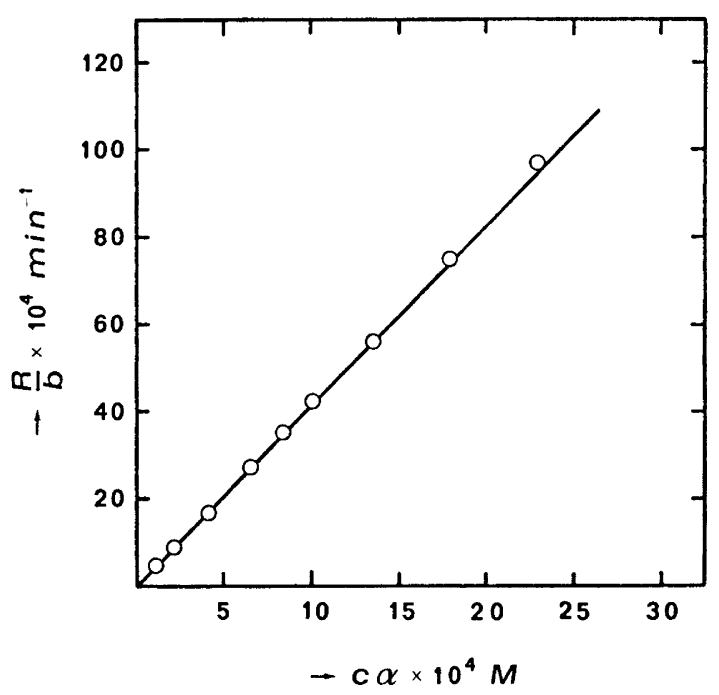

Fig. 1. Graph of $R / b$ vs. $c \alpha$ for the exchange of ${ }^{131} \mathrm{I}$ between butyl iodide and CsI in dry acetone at $25^{\circ} \mathrm{C}$ using values of $\alpha$ calculated according to the Fuoss-Onsager equation.

Acta Chem. Scand. 26 (1972) No. 4 
value of $R$ depends upon the last term in eqn. (4). In this case the experimental points should deviate more and more from the limiting tangent when the concentrations of the alkali iodides increase. In Fig. 1 this behaviour is illustrated.

If $k_{1}=0$, eqn. (4) can, after rearranging, be written

$$
k / \alpha=k_{\mathrm{i}}+k_{\mathrm{m}}(1-\alpha) / \alpha
$$

and becomes the Acreee quation. ${ }^{20}$

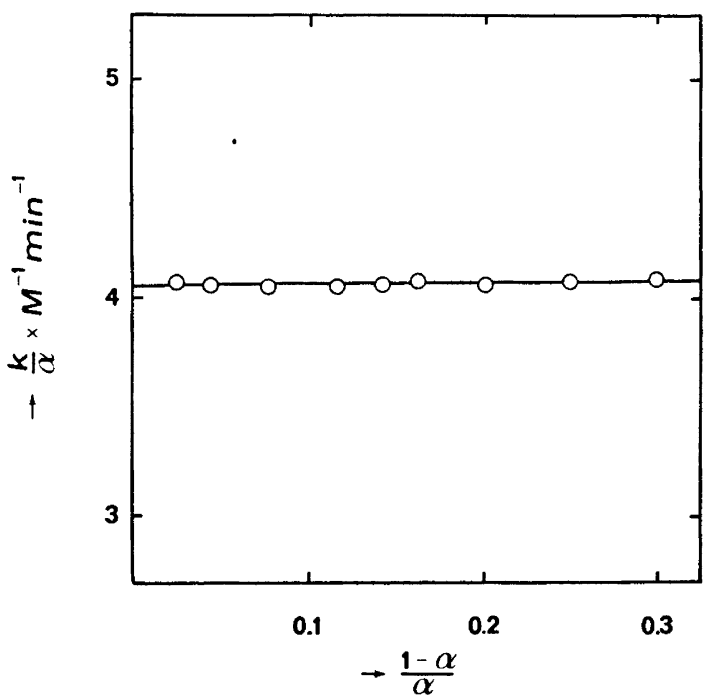

Fig. 2. Graph of $k / \alpha$ vs. $(1-\alpha) / \alpha$ for the same reaction as in Fig. 1 .

Table 6. Second-order specific rates, $k_{\mathrm{i}}$ and $k_{\mathrm{m}}$, for the exchange of iodine between butyl iodide and alkali iodides in acetone at $25^{\circ} \mathrm{C}$.

\begin{tabular}{|l|c|c|c|c|}
\hline Salt & $\begin{array}{c}K_{\mathrm{A}} \\
\mathrm{M}^{-1}\end{array}$ & $\begin{array}{c}k_{\mathrm{i}} \\
\mathrm{M}^{-1} \mathrm{~min}^{-1}\end{array}$ & $\begin{array}{c}k_{\mathrm{M}} \\
\mathrm{M}^{-1} \mathrm{~min}^{-1}\end{array}$ & $\begin{array}{c}\left.\left(k_{\mathrm{M}} / k_{\mathrm{i}}\right) \times 100\right) \\
\%\end{array}$ \\
\hline $\mathrm{NaI}$ & $124^{a}$ & $4.246 \pm 0.025$ & $-0.481 \pm 0.158$ & $-11.3 \pm 3.8$ \\
& $155^{b}$ & $4.288 \pm 0.022$ & $-0.175 \pm 0.124$ & $-4.1 \pm 2.9$ \\
$\mathrm{KI}$ & $120^{a}$ & $4.158 \pm 0.013$ & $-1.008 \pm 0.081$ & $-24.2 \pm 2.0$ \\
& $167^{b}$ & $4.192 \pm 0.014$ & $-0.190 \pm 0.070$ & $-4.5 \pm 1.7$ \\
$\mathrm{RbI}$ & $192^{a}$ & $4.099 \pm 0.020$ & $-0.164 \pm 0.110$ & $-4.0 \pm 2.7$ \\
& $228^{b}$ & $4.123 \pm 0.024$ & $0.102 \pm 0.118$ & $+2.5 \pm 2.9$ \\
$\mathrm{CsI}$ & $264^{a}$ & $4.126 \pm 0.015$ & $0.272 \pm 0.088$ & $+6.6 \pm 2.2$ \\
& $312^{b}$ & $4.142 \pm 0.013$ & $0.547 \pm 0.067$ & $+13.9 \pm 1.7$ \\
\hline
\end{tabular}

${ }^{a}$ Fuoss-Onsager conductance equation.

${ }^{b}$ Shedlovsky conductance equation.

The method of least squares was used to evaluate $k_{\mathrm{i}}$ and $k_{\mathrm{m}}$ in eqn. (6). The results are given in Table 6. All errors are standard deviations. It can be seen from Table 6 , that $k_{\mathrm{i}}$ is relatively insensitive to the choice of $K_{\mathrm{A}}$. The 
difference, for instance, in $K_{\mathrm{A}}$ for potassium iodide in acetone, according to the two conductance equations, is about $40 \%$ but the difference in the corresponding $k_{\mathrm{i}}$-values is less than $1 \%$. On the other hand, $k_{\mathrm{m}}$ is much more sensitive to the choice of $K_{\mathrm{A}}$, as can be seen in Table 6 .

From the last column in Table 6 it can be seen that most of the values in this column are negative. This "negative ion-pair reactivity" can be interpreted in terms of a kinetic salt effect.

In calculating the second-order specific rates, $k_{\mathrm{i}}$ and $k_{\mathrm{m}}$, according to eqn. (6), these two quantities have been regarded as independent of the ionic strength. This is probably a poor assumption, particularly for $k_{\mathrm{i}}$. Experimentally it is observed that $k$, which is a function of $k_{\mathrm{i}}, k_{\mathrm{m}}$, and $\alpha$, decreases with increasing ionic strength $(c \alpha)$ (see Table 2 and several examples in the literature, e.g., Refs. 21-24). This change of $k$ with concentration of the inorganic salt might be interpreted in two ways.

Firstly it may be a consequence of the increase of ionic association with increasing concentration and the different reactivities of free and paired ions. This has been discussed above. Secondly the reason may be a kinetic salt effect (changes in activity coefficients of reactants and transition-state complex). Neglect of the salt effect leads to an underestimate of the specific rate reaction of the paired ions, as has previously been pointed out. ${ }^{4}$ For the present, the latter effect must be neglected due to the lack of an exact correction method.

The last column in Table 6 also indicates that ion-pairs of cesium iodide may be kinetically active but the results are too uncertain to be the basis of any further conclusions. The extreme $k_{\mathrm{m}}$-value for KI may be a consequence of a too low $K_{\mathrm{A}}$-value.

In the derivation of eqn. (6) it is assumed that $k_{\mathrm{i}}$ is independent of the nature of the cation. This investigation supports this assumption. The deviations from average $k_{\mathrm{i}}$-values for potassium, rubidium, and cesium iodide fall within the limits of experimental errors. For sodium iodide the deviation is greater (about $2.5 \%$ from the average of the four $k_{\mathrm{i}}$-values), but not great enough to infer that sodium-ion has any significance in this respect.

Acknowledgements. The authors thank Dr. Per Beronius for valuable discussions and the Swedish Natural Science Research Council for financial support.

\section{REFERENCES}

1. Beronius, P. Acta Chem. Scand. 23 (1969) 1175.

2. Beronius, P., Isacsson, U. and Nilsson, A.-M. Acta Chem. Scand. 24 (1970) 189.

3. Beronius, P., Nilsson, A.-M. and Wikander, G. Acta Chem. Scand. 24 (1970) 2826.

4. Beronius, P. and Pataki, L. J. Am. Chem. Soc. 92 (1970) 4518.

5. Smith, S. G., Fainberg, A. H. and Winstein, S. J. Am. Chem. Soc. 83 (1961) 618.

6. Robinson, R. A. and Stokes, R. H. Electrolyte Solutions, Butterworths, London 1965, p. 458 .

7. Robinson, R. A. and Stokes, R. H. Electrolyte Solutions, Butterworths, London 1965, p. 461 .

8. Weissberger, A., Ed., Technique of Organic Chemistry, 3rd Ed., Interscience, New York 1959, Vol. I, Part I, Chap. IV.

9. Weissberger, A., Ed., Technique of Organic Chemistry, 3rd Ed., Interscience, New York 1959, Vol. I, Part I, Chap. XII.

Acta Chem. Scand. 26 (1972) No. 4 
10. Beronius, P. Trans. Roy. Inst. Technol. Stockholm, No. 213 (1963).

11. Beronius, P. Acta Chem. Scand. 15 (1961) 1151.

12. Beronius, P. Z. physik. Chem. (Frankfurt) 40 (1964) 33.

13. Beronius, P. Z. physik. Chem. (Frankfurt) 42 (1964) 45.

14. Nilsson, A.-M., Wikander, G. and Beronius, P. Acta Chem. Scand. 24 (1970) 1175.

15. Lind, J. E., Zwolenik, J. J. and Fuoss, R. M. J. Am. Chem. Soc. 81 (1959) 1557.

16. McKay, H. A. C. J. Am. Chem. Soc. 65 (1943) 702.

17. Fuoss, R. M. and Onsager, L. J. Phys. Chem. 61 (1957) 668.

18. Fuoss, R. M. and Accascina, F. Electrolytic Conductance, Interscience, New York 1959 , pp. $229-230$.

19. Beronius, P., Wikander, G. and Nilsson, A.-M. Z. physik. Chem. (Frankfurt) 70 (1970) 52 .

20. Acree, S. F. Am. Chem. J. 48 (1912) 352.

21. Evans, C. C. and Sugden, S. J. Chem. Soc. 1949270.

22. Bowers, S. D. and Sturtevant, J. M. J. Am. Chem. Soc. 77 (1955) 4903.

23. Lichtin, N. N. and Rao, K. N. J. Am. Chem. Soc. 83 (1961) 2417.

24. Bruce, W., Kahn, M. and Leary, J. A. J. Am. Chem. Soc. 87 (1965) 2800.

Received August 18, 1971. 